\title{
AC 2009-1482: INTRODUCTION TO ENGINEERING DESIGN: AN EMPHASIS ON COMMUNICATION
}

\section{Taryn Bayles, University of Maryland, Baltimore County}

Taryn Bayles is a Professor of the Practice of Chemical Engineering in the Chemical and Biochemical Engineering Department at UMBC, where she incorporates her industrial experience by bringing practical examples and interactive learning to help students understand fundamental engineering principles. Her current research focuses on engineering education, outreach and curriculum development. 


\section{Introduction to Engineering Design: An Emphasis on Communication}

For the last eight years, the Introduction to Engineering Design course at the University of Maryland Baltimore County (UMBC) has evolved from a traditional lecture and design-onpaper course, to an active learning lecture and project-based learning engineering design course. The importance of learning teamwork skills and communication skills are emphasized in the course. Every effort is made to ensure that the design teams are diverse, interdisciplinary, yet academically balanced. The design teams are required not only to research, design, construct, evaluate, test and present (through oral presentation and written reports) their product, but also to develop a mathematical model to predict their product's performance. It is important that the students have a fun yet inexpensive product to design and build, but they must also develop a mathematical understanding of the fundamental engineering principles that make their design work. Through this mathematical modeling the students cultivate the connection between mathematics, science and engineering. Successful engineering design projects have included human powered pumps, hot air balloons, hemodialysis systems, chemically powered vehicles, renewable energy systems and contaminated water purification systems. Videos of product testing have been made of each of the design projects and will be featured.

Over the years it has been observed that the students often overlook the importance of communication during the design process. Therefore, in the fall 2008 semester the teams were also evaluated on their ability to effectively communicate their design with their team members and with other teams in their discussion session. The class consists of 210 students; broken into seven discussion sessions, with five teams each - for a total of 35 design teams. The communication criteria was assessed in addition to the design project criteria. Each team was required to complete their design, mathematical model and testing plans well in advance to their scheduled testing date. Each team gave their design project construction materials and design plans (which include CAD drawings and instructions) to another team in the class which constructed the design. The construction team had one week to construct the design and then passed the constructed design to an evaluation team. The evaluation team tested and evaluated the design based on the testing / evaluation documentation provided by the original design team (the original design team constructs and evaluates two different designs while their design is worked on by other teams). Three days later the evaluation team returned the design, with the construction and evaluation reports to the original design team. The design team then had time to make any necessary modifications / improvements before the final demonstration / testing / evaluation of their design with the instructor. It was hoped that this rotation of the designs within the discussion session will facilitate better communication (both written and oral) between the teams and more successful designs; since each team is required to work on three different designs. The success (or failure or - logistical nightmare) of the communication criteria of the project is assessed with student surveys, written project report scores and oral presentations. Comparisons are made with previous semester surveys and scores when the designs did not rotate between the teams in each discussion session. 


\section{Background}

The Introduction to Engineering Design course (ENES 101) at UMBC was revamped in 2000 from a traditional lecture and design-on paper course to a project-based learning engineering design course. The students must work in interdisciplinary teams to design, build, evaluate, test, report (both a formal written report and oral presentation) and develop a mathematical model for a specified product. ENES 101 is a three-credit freshman engineering course which consists of two fifty-minute class sessions and a two-hour discussion session each week over a 16 week semester. The current enrollment in this course is approximately 210 students in the fall semester and 150 students in the spring semester. A new variation of this course was added in the fall 2003 and expanded in the fall 2004-8 semesters, as part of the FirstYear Success Courses initiative at UMBC, and was described previously ${ }^{(1)}$. Two sections of ENES 101 during the fall 2008 semester were designated as First-Year Success Courses and one Honors section was restricted to Honors College or Engineering Scholar students.

Each year a different design project is assigned and the students must research, design, construct, and develop an analytical model and then test, evaluate, and report on the product. The goal is to select a product that is fun, inexpensive to construct, simple, and yet requires fundamental engineering principles. Safety is the primary concern, and the design specifications are structured to include safety precautions. The projects are also structured to have "bragging rights" associated with the product performance. This has resulted in friendly competition among the teams, but is not a grading criteria. Successful projects have included: human powered pumps ${ }^{(2)}$, catapults or trebuchets for launching water balloons ${ }^{(2)}$, hot air balloons ${ }^{(3)}$ (adapted with permission), wooden block transport devices ${ }^{(4)}$ (adapted with permission), hemodialysis systems $^{(5)}$, and chemically powered vehicles ${ }^{(6)}$ (adapted with permission), renewable energy systems ${ }^{(5)}$ and contaminated water purification systems. The design project is introduced during class by having the students participate in hands-on reverse engineering activities. Many teams have created videos they made during the construction and testing of their projects. UMBC's Office of Information Technology has also filmed the design process over the course of the semester and has produced various videos which have been posted on YouTube.

Communication skills are stressed as part of the design project experience. Each team must complete a logbook ${ }^{(7)}$ (design notebook) over the course of the semester; the first team assignment is to interview each team member and log the interviews. The remainder of the entries serves as documentation of team meetings, evolution of design, modeling, evaluation approaches, and actual performance. Each team must also submit a final written report summarizing their efforts. Guidelines for the report, as well as a detailed grading rubric ${ }^{(8)}$ are handed out and discussed during class. The teams are encouraged to turn in a preliminary draft of their report for comments (this is a requirement for the First Year Success sections) prior to submitting their final report. UMBC also has a Writing Center located in the Learning Resource Center on campus that provides assistance to the students in the preparation of their reports. Each team is also required to make a formal oral presentation using PowerPoint at which each team member is required to present (the First Year Success sections are also required to give a practice presentation prior to their formal oral presentation with the instructor). Specific guidelines for the presentation are discussed in class and the students are also given a grading 
rubric for the presentation. Each team member must also complete a peer evaluation for themselves and each team member, which is part of the students' grade for the course. If the average peer evaluation for an individual student is less than $70 \%$; then their design report grade is appropriately weighted.

Starting in 2007-8 academic year, UMBC began charging a laboratory fee of $\$ 40.00$ per student for this course. Consequently, the design teams are provided materials order forms (along with a list of venders from which they can order their construction materials) and each team was required to submitt the materials order form to the instructor. The due date of the materials order form provided one of the design project milestones of the project whose intent is to ensure teams would refrain from delaying work on their project. Since communication was the theme of this year's design project, the teams were also provided detailed requirements for the construction and evaluation/testing memos which each design team received the respective teams and had to include (and discuss) in their formal design report and presentation.

\section{The Project Based Learning Design Projects}

The primary concern for each of the design projects is safety; considerable amount of time is spent each semester discussing safety issues specific to each project. Since the primary criterion for each design project is safety; each design product must operate without any hazards. The following is a brief description of the design specifications of the design projects.

\section{Wireless Sensor}

The design teams were challenged to design, construct, evaluate and test a wireless sensor. This wireless sensor design project was modified with permission from a freshman design project which has been successfully used at the University of Vermont ${ }^{(9,10)}$. The teams were challenged to design an inexpensive wireless sensor/transmitter device. Each team was required to choose and justify an application for which a wireless sensor would be appropriate. The teams had to design and develop a CricketSat-based system to meet the application's needs bearing in mind any unique constraints it imposed. The transmitted information signal had to be received and demodulated to demonstrate the accuracy of the sensor. Specifically the minimum design criteria of the sensor is that the system must serve an application where wireless sensing is an enabler; the system had to use the CricketSat platform; and the system required the design of a mechanical structure. The cost of the sensor/system had to less than $\$ 50.00$ (considering all materials purchased new, as if the team was prototyping the system for production - i.e., even if the team used 'found' materials, they had to cost them as if they were new). Non-functional decorations did not need to be included in the cost (i.e., pencil, paint, marker, stamps, decals, etc.). No pre-manufactured sensor/receiver system could be used.

Product performance: "Bragging rights" for the system was assessed using the following performance criteria: ["Bragging rights" were part of the project to encourage friendly competition between the design teams for the entire class and were not used to determine the design project grade; in addition, ties in each category are allowed.] 


\section{Engineering communication points $\quad x \quad$ Accuracy Index $\quad x \quad$ Cost Index}

- Engineering Communication was evaluated by how well the construction team and evaluation team was able to successfully construct and test / evaluate the design. The table below provides the list of parameters that were used in the evaluation of the design team's ability to communicate their design. Teams that did well for each parameter scored the maximum number of points; the construction and evaluation teams assigned the engineering communication points to the design teams.

\begin{tabular}{|ll|}
\hline Construction instructions & 10 \\
\hline Testing / evaluation instructions & 10 \\
\hline Initial testing accuracy & 10 \\
\hline
\end{tabular}

- Accuracy was an important factor in the design of the wireless sensor system. Each team had to demonstrate / test / evaluate the performance of their system. The accuracy index used to determine the final system performance was:

\section{Your Team's Sensor Performance Measured versus Actual (out of 100 points) 100 Points}

- Cost was also used to evaluate the performance of the design. All costs of components used in the system had to be accounted for and totaled by each team to find the total cost of the design. The cost index is used to stress the importance of creating a successful design which meets the minimum design criteria, yet minimizes costs. A cost index of 1.0 is most desirable. The cost index used to determine the final system performance was:

Minimum TOTAL cost of sensor that meets the design criteria \& a minimum of 20 Engr. comm. pts. Your Team's TOTAL design cost

Unfortunately the circuit boards which were to be used for the base of the CricketSat circuit were not received from the vendor in a timely fashion, and therefore a week later a second design project was made available for the design teams to design as an alternative. Each design team was allowed to either design the wireless sensor or a hot air balloon.

\section{Hot Air Balloon}

The hot air balloon design project was to design, construct, model, predict the performance, test and evaluate a hot air balloon. The hot air balloon was powered by a groundbased hair-dryer-type heat gun, and was required to stay aloft a minimum of 20 seconds; carry a minimum payload of 15 grams; and was restricted in size to (while in free flight), (including all attached items) fit completely inside a 2 meter cube. In addition the cost of the hot air balloon had to be less than $\$ 50.00$ (considering all materials purchased new, as if the team was prototyping the system for production - i.e., even if the team used 'found' materials, they had to 
cost them as if they were new). Non-functional decorations did not need to be included in the cost (i.e., pencil, paint, marker, stamps, decals, etc.). The teams were not allowed to use any source of thermal, potential, chemical or mechanical energy other than the ground-based hot air supply provided. Each team was allotted 15 minutes to setup the balloon at the launch site, 5 minutes to pre-inflate the balloon (using an ordinary hair dryer - also provided), up to five minutes of thermal heating using the heat gun, which was followed by the actual launch. Each team was required to create a mathematical model, (using Excel or MatLAB) that predicted how long the hot air balloon would ascent. The teams could either mathematically model the time of descent or input the actual time of descent from testing to predict the total time aloft. Inputs to the model had to include the weight of the balloon, payload, balloon surface area and volume, balloon material thermal conductivity, balloon inside air temperature at lift-off, testing site ambient air temperature, etc. This mathematical model is an important component of the design project so that the students cultivate the connection between math, science and engineering. Specifically this ensures that the project goes beyond a 'junkyard wars' approach to design but fosters the students understanding of unit conversions, the ideal gas law, buoyancy, heat transfer, etc. The students are concurrently taking classes in Chemistry, Physics and Math and these topics are covered in these classes while they are con-currently taking ENES 101. [The primary grading criteria of the formal written report and oral presentation is an assessment of the student's understanding of the underlying principles of engineering, math and science of their design project.] Each mathematical model was emailed to the instructor and checked for its functionality and correctness prior to testing.

Product performance: "Bragging rights" for the hot air balloon design project was assessed using the following performance criteria:

\section{Engr comm points $x$ Time aloft (s) $x$ Payload (g) $x$ Model Accuracy $x$ Cost Index}

- Engineering Communication was evaluated by how well the construction team and evaluation team was able to successfully construct and test / evaluate the design. The table below provides the list of parameters that were used in the evaluation of the design team's ability to communicate their design. Teams that did well for each parameter scored the maximum number of points; the construction and evaluation teams assigned the engineering communication points to the design teams.

\begin{tabular}{|ll|}
\hline Construction instructions & 10 \\
\hline Testing / evaluation instructions & 10 \\
\hline Initial testing accuracy & 10 \\
\hline
\end{tabular}

- Model Accuracy was calculated using the SMALLER of:

$$
\left|\frac{\text { Predicted Time Aloft }}{\text { Actual Time Aloft }}\right| \quad \text { or } \quad\left|\frac{\text { Actual Time Aloft }}{\text { Predicted Time Aloft }}\right|
$$


- Cost was also evaluated when judging the performance of the design. All costs of materials used in the hot air balloon had to be accounted for and totaled by each team to find the total cost of the design. The cost index is used to stress the importance of creating a successful design which meets the minimum design criteria, yet minimizes costs. A cost index of 1.0 is most desirable. The cost index used to determine the final project performance was:

\section{Minimum TOTAL cost of a hot balloon that meets design criteria \& minimum of 20 Engr Comm pts} Your Team's TOTAL design cost

\section{$\underline{\text { Results and Conclusions }}$}

UMBC has revamped the introduction to engineering design course to include hands-on project-based inquiry experience in the design of a specified product. The fall 2008 ENES 101 design teams had two different design projects to select from and almost $25 \%$ of the teams elected to build the wireless sensor project and over $75 \%$ of the teams elected to design the hot air balloons. The wireless sensor design projects included wireless door alarms, light sensors, altimeters, wireless range expanders and pressure sensors. Some of the wireless sensors and hot air balloon designs are shown in Figures 1 and 2.

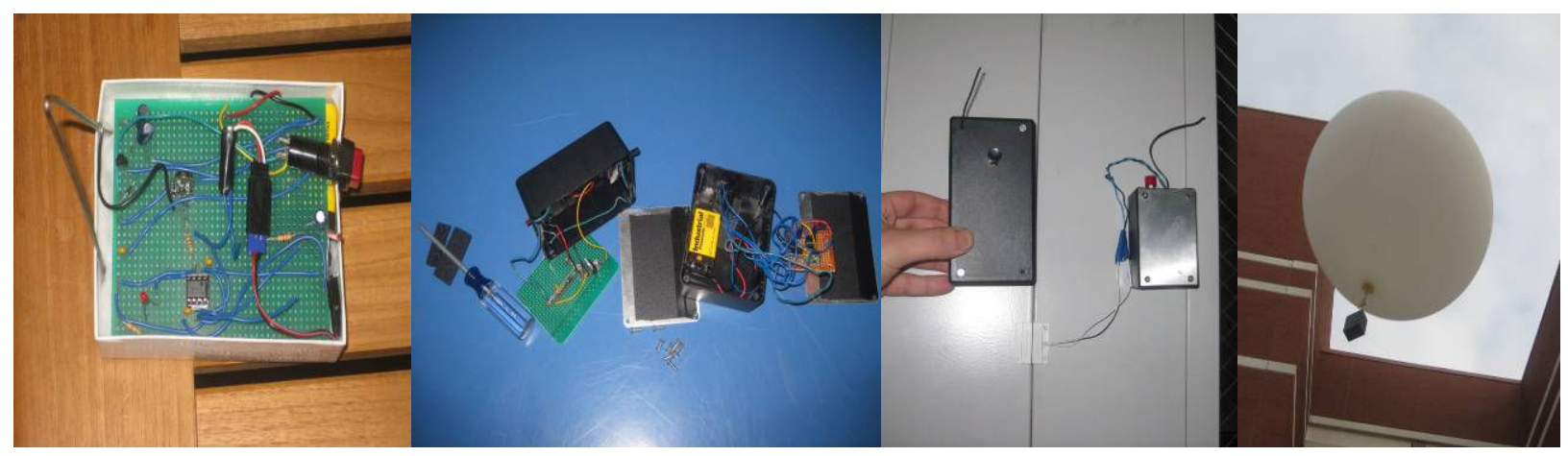

Figure 1. Various wireless sensor design projects.

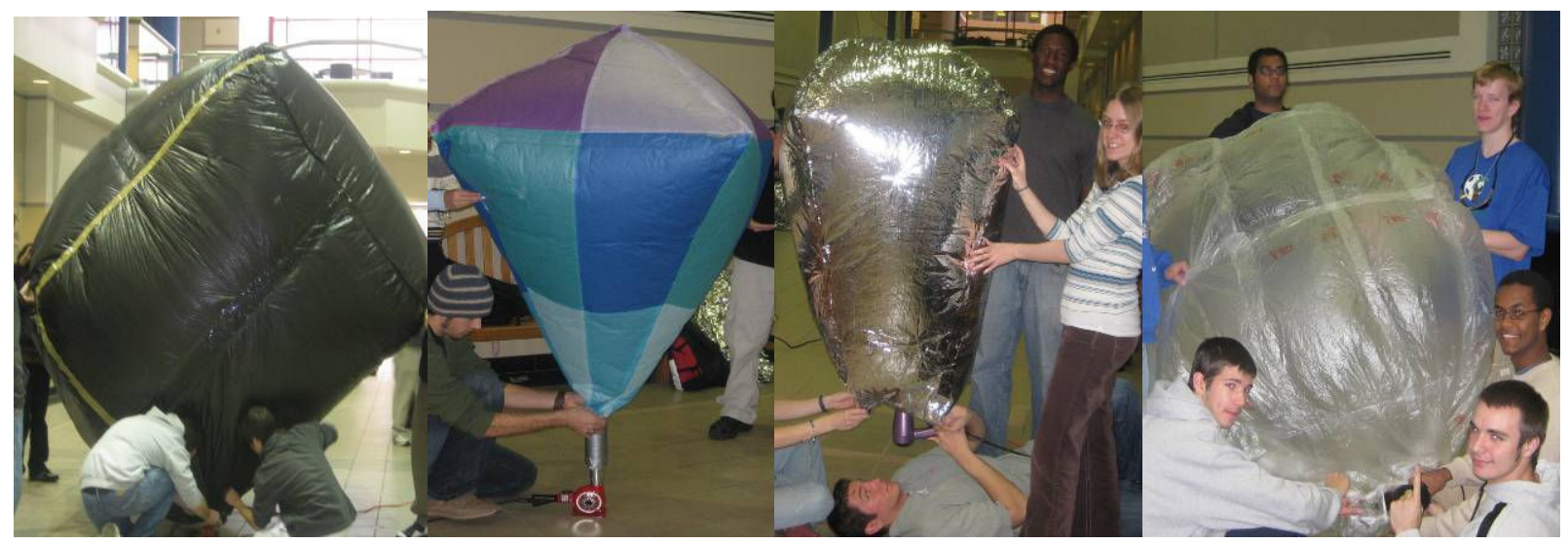

Figure 2. Various hot air balloon designs. 
As a metric of the effectiveness of the course, some key criteria established by ABET for assessing engineering programs are used. Our department has adopted the five C's; competency in the discipline, critical thinking ability, cooperation with teammates, communication - both written and oral, and capacity for lifelong learning. At the beginning of each semester a course objectives worksheet is provided to each student which indicates the ABET criteria which will be covered over the course of the semester. Although it is unlikely that a single freshman engineering course can prepare students to satisfy the ABET criteria, it is a useful tool to gauge students' progress in their ability to utilize key engineering concepts and thought processes. To this end, students are asked to provide a self assessment, via a survey, of their progress in key ABET areas which were part of the course. Survey results from the fall 2008 semester are provided with previous semesters are provided in Table 1 and are used to assess if there was a difference in the student's perception of the communication portion of the course.

Table 1: Student Assessment of ABET criteria; Competency, Critical Thinking, Cooperation with Teammates, Communication and Capacity for Life-Long Learning.

\begin{tabular}{|c|c|c|}
\hline \multicolumn{3}{|l|}{ Student Assessment of Course Outcomes } \\
\hline & Prev. Sem. & Fall 2008 \\
\hline & $\mathrm{n}=182$ & $\mathrm{n}=194$ \\
\hline \multicolumn{3}{|l|}{ Competency } \\
\hline Ability to use math or science & 3.78 & 3.89 \\
\hline Proficiency in engineering & 3.09 & 2.94 \\
\hline Ability to design process using engineering principles & 3.23 & 3.21 \\
\hline $\begin{array}{l}\text { Ability to use the techniques, skills and modern engineering tools } \\
\text { necessary for the practice of engineering }\end{array}$ & 3.31 & 3.23 \\
\hline \multicolumn{3}{|l|}{ Critical Thinking } \\
\hline Ability to analyze/solve open ended problems in engineering & 3.19 & 3.10 \\
\hline Ability to evaluate solutions or designs given constraints & 3.87 & 3.94 \\
\hline \multicolumn{3}{|l|}{ Cooperation with Teammates } \\
\hline $\begin{array}{l}\text { Ability to work effectively in teams with others having different } \\
\text { backgrounds }\end{array}$ & 4.34 & 4.29 \\
\hline Ability to fill both leadership and supporting roles in a team & 4.22 & 4.30 \\
\hline \multicolumn{3}{|l|}{ Communication } \\
\hline Ability to communicate effectively in written form & 3.90 & 4.05 \\
\hline Ability to communicate effectively in an oral form & 3.96 & 4.07 \\
\hline \multicolumn{3}{|l|}{ Capacity for Life-Long Learning } \\
\hline Ability to define problem given an open-ended questions or situation & 3.95 & 3.89 \\
\hline Ability to locate tools and information relevant to a given problem & 3.96 & 3.92 \\
\hline Ability to assimilate information relevant to a problem & 3.95 & 3.95 \\
\hline $\begin{array}{l}\text { Ability to assess your own ability/knowledge to solve a problem and } \\
\text { determine when to seek help }\end{array}$ & 4.08 & 4.16 \\
\hline
\end{tabular}


The survey measures the students' self-perceived attitudes and comfort level in key ABET areas. The SACO (Student Assessment of Course Outcomes) data has been consistent over the last eight years ever since the course evolved from a traditional lecture and design-onpaper course to an active learning lecture and project-based learning engineering design course. Not surprisingly, the students always rate the cooperation with teammates category the highest. There was a slight increase in the communication component of the course in the fall 2008; however, this increase was not statistically significant $(\mathrm{p}>0.05)$. A t-test was performed on all of the course outcomes data and none of the assessments were found to be statistically significantly different from the previous semester to the fall 2008 semester. The proof of the students progress, however, can be readily seen in the working products they design and produce in their engineering design projects.

The Learning Resources Center at UMBC has a program in place through which they ask instructors of first semester freshmen to identify students that are in danger of failing at the midpoint of the semester. Over sixty percent of the students in the fall 2008 ENES 101Y (First Year Success sections of the course) were identified at the end of October, as failing the course. However, by the end of the semester and with the assistance of the success strategies as previously discussed $^{(1)}$, less than ten percent of the students in ENES 101Y failed the course, and is comparable to the other sections of the course (with the exception of the Honors section - in which none of the students failed the course). The most significant impact of the success component of the course (over the last four years) has resulted in that $50 \%$ of the students in the ENES $101 Y$ course improved their GPA's from the fall to the spring semesters (versus less than $15 \%$ for the students in the other sections of ENES 101).

As part of the formal design report, the students were required to provide construction / assembly instructions complete with a CAD drawing package. The average score on this section of the report was $63.2 \%$ in previous semesters, and was $73.7 \%$ during the fall 2008 semester (when assembly instructions were provided to the construction teams and also required in the formal report). A t-test conducted on the data sets showed that the increase in scores was statistically significant $(\mathrm{p}<0.05)$. In addition, each team is also required to give an oral presentation for their design project. The students are provided detailed grading rubric for the presentation. Each presentation is required to be 12 minutes in length and 3 minutes for questions and answers (which are part of the presentation grade). In previous semesters, there has never been more than handful of questions (each semester for all of the discussion sessions) from students in the class; the questions have predominately come from the instructor, teaching fellows and graduate student graders. The fall 2008 semester was a complete contrast - the students from the other teams in the class asked the majority of the questions during the entire Q\&A portion of the presentations. It was obvious that the students were engaged and interested in the other teams design evolution due to the rotation of projects within the discussion sessions.

At the conclusion of the course, the students were asked to complete a survey regarding the communication portion of the design project. The results of their survey questions are provided in Table 2 . 
Table 2: Student Survey Responses - ENES 101 Design Project Communication

\begin{tabular}{|c|c|c|}
\hline \multicolumn{3}{|l|}{ Student Survey Responses } \\
\hline Question & Yes & No \\
\hline $\begin{array}{l}\text { Did your team construct and test your design project prior to giving the } \\
\text { materials and instructions to the construction team? }\end{array}$ & $68 \%$ & $32 \%$ \\
\hline $\begin{array}{l}\text { Did your team re-design/re-construct your design project prior to giving the } \\
\text { design and instructions to the testing/evaluation team? }\end{array}$ & $40 \%$ & $60 \%$ \\
\hline If yes, did your re-design use the suggestions from the construction team? & $75 \%$ & $25 \%$ \\
\hline $\begin{array}{l}\text { Did your team re-design/re-construct your design project prior to the final } \\
\text { testing date? }\end{array}$ & $45 \%$ & $55 \%$ \\
\hline $\begin{array}{l}\text { If yes, did your re-design use the suggestions from the testing/evaluation } \\
\text { team? }\end{array}$ & $75 \%$ & $25 \%$ \\
\hline
\end{tabular}

The students were also asked to provide comments on the following questions (the consensus response is indicated in italics after each question): Please note: not all of the students provided comments and/or their written response did not necessarily agree with their survey response.

- Did the construction/testing/evaluation of the design by other teams within your class require your team to finalize your design at an earlier date as compared to if your team would have had the sole responsibility of constructing/testing/evaluation your design?

Most of the students indicated that they did begin their projects at an earlier date since part of their grade was dependent upon them giving their design and materials to the construction team and then the evaluation and testing plan to the next team, which were prior to their own actual testing date. There were some students, however, who felt that they would have started the project at the same time, regardless of the rotation of the projects.

- Did the communication component (requirement of providing written instruction - and sometimes also a team member for consultation) of this design project contribute positively to your design project (either the design or the report or both)?

Most students indicated that having to provide the written instructions caused them to think more about the instructions when writing them for the construction and evaluation teams, and felt that this task contributed positively to their written report grades.

- Did the communication component (requirement of receiving feedback from the construction/testing/evaluation teams) of the design project contribute positively to your design project (either the design or the report or both)?

Most students indicated that the suggestions from the construction/testing/evaluations teams were limited (if at all) and were only seldom used for re-design of the project. However, there were some students who indicated that they received very useful suggestions from the teams and were able to incorporate these suggestions into their final designs.

- What did you like and dislike about the communication / construction / testing evaluation team components of this design project?

Likes: The students liked the design projects and thought that it was a fun experience. They indicated that the communication requirement made it seem more like a real-world 
requirement. It also gave them the opportunity to see different designs in more detail which resulted in them thinking more carefully about their own design and re-design.

Dislikes: Many students were frustrated that another team constructed their project and felt that the other teams didn't do a very good job working on their project... or that many teams did not provide much feedback, or justification of the scorelevaluation they assigned to the design team. Some students felt that the project was too much work for an introductory course and not all team members contributed equally to the project (this is a very common complaint in previous semesters as well).

Despite some of the student's comments, it was observed that the students did start working on the design projects at a much earlier date as compared to previous semesters. The usual design project 'panic' (flooding of questions regarding the project; borrowing of materials and equipment; the author's lab being filled with teams working on their projects; etc.) started at least two-to-three weeks prior to these events in previous semesters. It was also observed that a higher percentage (77\% versus $65 \%$ ) of the designs were successful in meeting the minimum design criteria. There is no doubt that the communication component of the design project came with a higher number of student complaints concerning the design project (specifically concerning the non-cooperation of construction and testing/evaluation teams meeting the expectations of the design teams) and - it did lead to more confusion as to the due dates of the various components of the project and - at best - it was a logistical nightmare. However, based on the many years that the author has spent in industry as a design engineer, it was a valuable and more realistic design experience for the students. The communication component of the design project will be incorporated in future ENES 101 classes.

\section{References}

1. Bayles, T. M., "Improving the Freshman Engineering Experience”, ASEE paper \#1602, 2004.

2. Bayles, T.M., "Project Based Learning Design Projects for Introduction to Engineering Design Courses", ASEE Paper \#1381, 2005.

3. Burrows, V., http://129.219.116.31/Featured_Lessons/con_lessons.html, accessed August 19, 2002 and personal communication August 2, 2002.

4. Merkey, C.T. and P. Brackin, "Gravity Powered Block Transport: A Freshman Design Project", Proceedings of the 2003 American Society of Engineering Educations Annual Conference \& Exposition.

5. Au, N., T.M. Bayles and J.M. Ross, "Exposing Chemical Engineering Students to Real World Problems: Health Care and Renewable Energy Systems", ASEE Paper \#2008-1005.

6. Patton, C. L. and L. Ford, "Chemically Powered Toy Cars: A Way to Interest High School Students in a Chemical Engineering Career," ASEE paper 2003-596.

7. Brand, J.I., "The Effective Use of Logbooks in Undergraduate Classes," Chemical Engineering Education, vol. 33, no. 3, 1999, pp. 222-231.

8. Boyd, G. and M.F. Hassett, "Developing Critical Writing Skills in Engineering and Technology Students," Journal of Engineering Education, vol. 89, no. 4, 2000, pp. 409-412.

9. Frolik, J. and T. Keller, "Wireless Sensor Networks: An Interdisciplinary Topic for Freshman Design," Proceedings of the 2005 American Society for Engineering Education Annual Conference \& Exposition, 2005.

10. Frolik, J. and M. Fortney, 'A Low-Cost Wireless Platform for First-Year Interdisciplinary Projects,' IEEE Transactions on Education, volume 49, No. 1, February 2006, pp. 105-112. 